\title{
Code-switching, swearing and slang: the colloquial register of Basque in Greater Bilbao
}

\author{
Hanna Lantto (University of Helsinki)
}

Code-switching between two languages or varieties, swearing and slang - all of them are mainly phenomena of spoken language and none of them is precisely the kind of speech parents, teachers or other authority figures traditionally have been fond of. However, the normative disapproval rarely succeeds in eradicating stigmatized forms of talk. Their function in building in-group solidarity, offering stylistic devices and, particularly in the case of swearing, providing emotional release is important and not easily replaceable. Romaine (1995: 294) notes that despite the negative prestige, many varieties persist partly because they serve as markers of in-group identity.

This paper discusses the relationship of swearing and slang with code-switching in Basque context. The study is based on 22 hours of recorded material with 22 Basque bilinguals, both L1 and L2 Basque speakers. In Greater Bilbao area even the bilinguals who do not frequently code-switch shift to Spanish to introduce slang or swear words into otherwise Basque discourse. The susceptibility of these elements to switching is examined from structural, pragmatic and sociolinguistic point of view. The phenomena are understood to strengthen one another: when a conversational move is marked in multiple ways, it becomes even more salient, thus underlining the intended effect. The co-occurrence of various devices stresses the informality of the colloquial speech also when used as part of a speech style. In this particular case, the Basque speakers of Greater Bilbao live scattered in a city area with a Spanish monolingual majority. The diversity in the linguistic backgrounds further complicates the development of colloquial Basque varieties. A common ground can be found in the colloquial Spanish expressions and the informality can be brought into Basque via code-switching.

\section{Reference}

Romaine, Suzanne (1995) Bilingualism. Oxford : Blackwell. Second edition. 